RESENHA

\title{
El saber práctico de los profesores especialistas: aportaciones desde las didácticas específicas
}

\author{
MÁRCIO RODRIGO DELFIM \\ Ministério Público do Estado de Goiás, Goiânia, GO, Brasil
}

\begin{abstract}
ARIZA, Rafael Porlán; TOSCANO, José Matín. El saber práctico de los profesores especialistas: aportaciones desde las didácticas específicas. In: MOROSINI, M. C. (Org.). Professor do ensino superior: identidade, docência e formação. Brasília: Plano Editora, 2001. p. 61-75.
\end{abstract}

Rafael Porlán Ariza e José Martín Toscano são professores do Departamento de Didática das Ciências da Universidade de Sevilha, Espanha, e membros do Grupo de Didática e Investigação na Escola (DIE) do projeto curricular Investigação e Renovação Escolar (IRES). Rafael Ariza é professor visitante do Programa de Pós-Graduação em Educação (PPGEdu) da Universidade Luterana do Brasil (Ulbra).

O texto resenhado intitula-se "El saber práctico de los profesores especialistas: aportaciones desde las didácticas específicas", compondo capítulo do livro Professor do ensino superior, identidade, docência e formação (Morosini, 2001, p. 61-75).

Os autores iniciam o texto em análise questionando: Que características deve ter o conhecimento profissional dos professores especialistas, na perspectiva de uma educação de qualidade?

Normalmente, o conhecimento profissional se organiza em torno dos conteúdos das diversas disciplinas, relegando a segundo plano aqueles saberes e habilidades mais relacionados com a atividade docente.

Apesar disso, todos os professores desenvolvem, inevitavelmente, um conhecimento tácito relacionado com os processos de ensino-aprendizagem, que em grande parte orienta e dirige sua conduta em sala de aula.

Esses dois componentes do conhecimento profissional dos especialistas possuem características epistemológicas claramente distintas:

- o saber acadêmico e disciplinar e

- o saber-fazer tácito. 
O primeiro é um conhecimento consciente, abstrato e racional, baseado na lógica da disciplina, com foco nos produtos da ciência. $\mathrm{O}$ segundo, pelo contrário, é um conhecimento tácito, concreto e irrefletido, baseado na lógica do pensamento cotidiano.

Essa situação resulta em uma significativa simplificação do conhecimento profissional impedindo os professores de abordarem seriamente a complexidade dos processos de ensino-aprendizagem das disciplinas. Tal simplificação se manifesta, entre outros, pelos seguintes aspectos:

- tendência de converter diretamente os conteúdos das disciplinas em conteúdos curriculares;

- visão dos conteúdos curriculares exclusivamente de maneira conceitual e acumulativa;

- tendência de considerar os alunos como receptores passivos de informação;

- separação reducionista que ocorre entre conteúdos e metodologias;

- fato de conceber a aprendizagem científica apenas por uma perspectiva individual;

- modelo de avaliação seletivo e sancionador.

É com base nessa perspectiva que os autores tratam dos desafios do novo conhecimento profissional. Para eles, é necessário definir um novo conhecimento profissional para a formação inicial e continuada dos professores, que leve em conta os problemas atuais do ensino das disciplinas, incorporando uma perspectiva mais didática na formulação e seleção de conteúdos curriculares, promovendo esquemas de atuação mais poderosos e fundamentados.

Concretamente, é necessário um profissional capaz de considerar as seguintes questões:

- Em relação à análise didática da disciplina, quais são os marcos conceituais de uma disciplina que são adequados para o seu ensino?

- Em relação à análise histórica da disciplina, que evolução histórica tem ocorrido e em torno de quais problemas fundamentais?

- No âmbito da análise da cultura e pensamento cotidiano, quais são as áreas de experiência social e cultural mais importantes em relação à área, assunto ou disciplina?

- Com base nos três pontos antes mencionados e em relação à concepção dos conteúdos escolares, qual é o conhecimento escolar desejável para os alunos em relação à disciplina em questão?

- Finalmente, sobre os procedimentos metodológicos que promovem a aprendizagem dos alunos e a evolução de suas concepções, que diretrizes metodológicas promovem a construção significativa do conhecimento no ambiente escolar?

Evidentemente, não é possível, no contexto deste artigo, dar uma resposta completa e profunda a todos esses problemas, porém os autores procuram definir as diferentes fontes que podem contribuir para a formação de um saber profissional capaz de abordá-los. 
O novo saber profissional deve organizar-se em esquemas de conhecimento teórico-prático de caráter integrador que se devem alimentar pelo menos destas quatro fontes de conteúdos profissionais:

- diversas disciplinas científicas relacionadas;

- diferentes disciplinas que estudam os problemas do ensino e da aprendizagem de uma forma geral;

- própria experiência;

- didáticas específicas que atuariam como disciplinas-síntese, que por sua vez integrariam as três dimensões anteriores.

As duas primeiras dimensões citadas, disciplinas científicas e psicopedagógicas, atuam no nível do saber acadêmico. A terceira, empírica, pretende também ampliar os esquemas de intervenção. Por último, as didáticas específicas estão em um nível epistemológico intermediário entre o saber formalizado e o saber-fazer empírico, formando o que poderíamos chamar de saber prático.

Em resumo, o novo saber profissional não é a mera soma de conhecimentos parciais de cada uma das fontes analisadas, mas sim o resultado de elaborar, partindo delas e dos problemas relevantes da profissão, um conhecimento genuíno, de caráter estritamente didático, prático, mas não puramente técnico, com reelaborações conceituais que sustentem princípios, esquemas e roteiros de atuação flexíveis, versáteis e dotados de um certo grau de complexidade.

Assim, para os autores, a proposta de conhecimento profissional desejável relaciona-se com um modelo de ensino baseado no construtivismo e na aprendizagem por investigação do aluno, bem como com um modelo de professor investigador de sua própria atuação docente.

Seguem algumas hipóteses sobre os professores especialistas:

1. Conhecer em profundidade o objeto de estudo, bem como os conceitos "pontes" com outras disciplinas próximas, isto é, aqueles conceitos que permitem a construção de interligações entre as mais diversas disciplinas (interdisciplinaridade).

2. Conhecer a história da ciência, com foco em sua disciplina, mas estabelecendo conexões em cada período histórico com o estado de coisas em outros ramos do conhecimento.

3. Ser iniciado em pesquisa, de modo que tenha alguma compreensão prática do que significa a metodologia científica.

4. Ter uma concepção epistemológica da ciência, do método científico e das outras formas de conhecimento, segundo os quais o conhecimento científico-disciplinar não é neutro, absoluto e superior, mas relativo, evolutivo e condicionado histórica e socialmente com um contexto particular de produção e aplicação, no âmbito do qual possui certa gama de validade.

5. Estabelecer relações significativas entre a disciplina na qual é especializado e os problemas socioambientais relevantes.

6. Saber como detectar, analisar e interpretar os indicadores externos de concepções e representações de seus alunos.

7. Formular um conjunto de metaconhecimentos, tais como o de "troca", "interação" ou "sistema", um conjunto de procedimentos gerais, tais como 
a capacidade de "reconhecer problemas", de "analisar e contrastar pontos de vista", e um conjunto de valores fundamentais, tais como "a autonomia", "a cooperação" e outros que servem como referenciais contínuos do processo de ensino-aprendizagem.

8. Elaborar também quadros ou mapas de conhecimentos, procedimentos e atitudes que relacionem informações procedentes de diferentes disciplinas científicas e problemas relevantes e interessantes para os alunos.

9. Pouco sentido tem todo o trabalho anterior, se não estiver relacionado com as concepções e representações dos alunos. Fazer isso envolve uma análise didática dos conteúdos, ampliando os limites do nosso próprio conhecimento profissional.

10. Projetar, implementar e avaliar atividades do seguinte tipo:

- acessar o pensamento espontâneo de estudantes e expandir a sua área de interesse;

- formular e definir os problemas de pesquisa;

- submeter as concepções dos alunos a contrastes e questionamentos;

- estruturar, implementar e generalizar as possíveis novas concepções construídas pelos alunos ao longo da investigação.

Por fim, os autores esclarecem que a proposta de conteúdos desse novo saber prático visa contribuir com algumas questões de interesse para o aprofundamento do debate sobre a formação de professores especialistas, a partir da rara perspectiva de considerar as didáticas específicas como disciplinas emergentes, com uma grande abertura interdisciplinar e com algum potencial de mediação epistemológica entre os saberes de natureza diferente.

\section{REFERÊNCIA}

Ariza, R. P.; Toscano, J. M. E1 saber práctico de los profesores especialistas: aportaciones desde las didácticas específicas. In: Morosini, M. C. (Org.). Professor do ensino superior: identidade, docência e formação. Brasília: Plano Editora, 2001. p. 61-75.

\section{SOBRE O AUTOR}

Marcio Rodrigo Delfim é doutorando em sustentabilidade social e desenvolvimento pela Universidade Aberta de Portugal. Professor do Ministério Público do Estado de Goiás.

E-mail:mrdelfim@gmail.com 